\title{
Treatment of bentonite fluid for excavation into Chalk
}

1 Carlos Lam DPhil, CEng, MICE, MHKIE Formerly Lecturer in Geotechnical Engineering, School of Mechanical, Aerospace and Civil Engineering, The University of Manchester, Manchester, UK (corresponding author: carloslam@hotmail.co.uk) (Orcid:0000-0003-3269-1638)

2 Stephan A. Jefferis PhD, CEng, CEnv, FICE, CGeol, FGS, FRSA Director, Environmental Geotechnics Ltd, Adderbury, UK; Visiting Professor, Department of Engineering Science, University of Oxford, Oxford, UK
3 Tony $\mathbf{P}$. Suckling MSC, CEng, FICE

Director, A-squared Studio Engineers Ltd, London, UK; formerly Technical Director, Balfour Beatty Ground Engineering, Basingstoke, UK
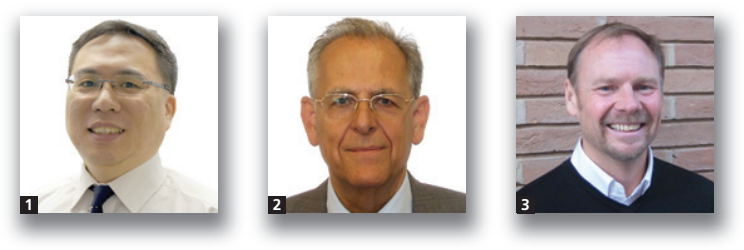

This paper is concerned with the treatment of a bentonite support fluid during excavations extending into Chalk. Chalk can disintegrate during the excavation process and can, like any other soil that may disperse into the slurry, significantly alter the properties of the fluid if it is not appropriately managed. A case history in Woolwich, East London is presented to highlight the necessity for treatment of the bentonite slurry used to support grounds that release fines. It was found that, with use of the solids-separation equipment, the slurry could be maintained within specification over the course of the project. Desanders, desilters and a centrifuge were necessary for slurry management during the works. At the end of the works, the centrifuge was used to separate the unwanted residual slurry into a paste and a centrate of near-clear water. Chemical analyses conducted on the centrate confirmed that it was comfortably within specification for disposal to a foul sewer and physical tests on the dewatered bentonite sludge confirmed that it was sufficiently stiff that it could be disposed as a solid waste along with other soil arisings. The centrifuge treatment thus eliminated the high costs of transport and disposal of unwanted bentonite slurry.

\section{Introduction}

Bentonite support fluids have been used on construction projects across the world for over 60 years. Over this time, contractors, consultants and academics have developed a considerable body of experience with the use of these fluids in bored piles, diaphragm walls and slurry tunnelling. Much of this experience has been summarised in technical guidance and specifications. For example, the Federation of Piling Specialists (FPS) in the UK has published and periodically updated a specification and associated control test procedures for bentonite support fluids for some four decades (FPS, 1975, 1977, 1985, 2000, 2006). These documents have been widely followed by practising engineers along with documents such as the ICE Specification for Piling and Embedded Retaining Walls (ICE, 1996, 2007, 2017). Specifications for bentonite support fluids are also available in other countries (e.g. AASHTO, 2017; GEO, 2006).

For many ground conditions, the properties of the bentonite support fluid can be controlled and maintained to within the required limits using desanders and, if necessary, desilters (Cowie and Crawley, 1989; Schlosser et al., 1989). However, special attention has to be paid to the management of slurries used to support excavations in soils that release significant amounts of fine soil particles. These particles can become suspended in bentonite slurry because of its viscosity and gel, which provide solids-carrying capacity. To avoid the slurry becoming too thick and dense, fines must be managed during the works, typically using soil-slurry separation plant such as desanders and desilters and, occasionally, centrifuges. This paper concerns the performance of a soil-slurry separation plant for a diaphragm wall project where the walls passed through the Thanet Formation and extended into a chalk which broke down to release significant amounts of fines.

Desanders combined with desilters are typically effective in removing soil particles to a useful extent only down to about $30 \mu \mathrm{m}$, although the actual solids-removal performance of a hydrocyclone will be strongly influenced by the solids content and viscosity of the fluid to be treated. It follows that finer treatment plant such as centrifuges may be necessary when excavating in grounds that release significant amounts of fine to medium silts and clay-sized material. In the past, it was possible to dispose of over-thick or over-dense slurries as liquid wastes. However, in many countries including the UK, liquid waste disposal to landfill has been banned. This has made the 
use of centrifuges cost-effective when compared with disposal of out-of-specification slurry for treatment by others off-site. It may be noted that although centrifuges are regularly used for the removal of fines in slurry tunnelling and pipe jacking (Hindmarch et al., 2008; Liu, 2010), their use is rarer for bored piling and diaphragm walling. Surprisingly, a survey of the literature on bored piles and diaphragm walls revealed little published information on the performance of desanders and desilters, let alone centrifuges. As a first step towards greater awareness of soil-slurry separation plant, this paper presents a case history of the use of bentonite support fluid for diaphragm walling and bored piling in soils including Chalk, which can break down to release a significant amount fines. The excavation was carried out for the construction of the Crossrail station at Woolwich, East London.

\section{Background}

\subsection{Ground conditions}

The new Woolwich station is located at the former Woolwich Arsenal site in East London. The geology at the site consists of $3 \mathrm{~m}$ of Made Ground and Terrace Gravels overlying $11 \mathrm{~m}$ of Thanet Sand with a $1 \mathrm{~m}$ thick Bullhead Bed at the base and then Chalk (Pennington, 2015; Symes, 2012). The groundwater level lies at $5-10 \mathrm{~m}$ below ground level. The particle size characteristics of the Thanet Sand, Bullhead Bed and the Chalk were of particular relevance to the slurry-supported excavation works at this site, so a brief description is now given. Thanet Sand is a fine sand and is known to have a higher fines content near the bottom of the stratum. Lam et al. (2014) carried out a sieve analysis of samples taken from the top of the Thanet Sand layer at Stratford, East London, and determined $D_{10}, D_{30}$ and $D_{60}$ values of $0 \cdot 07,0 \cdot 10$ and $0.14 \mathrm{~mm}$ respectively. A fuller discussion of the particle size distributions of Thanet Sand is given by Menkiti et al. (2015). The Bullhead Bed is a distinct unit that is commonly present at the base of the Thanet Formation and usually comprises angular to rounded coarse flint gravels in a sandy clay matrix. The flint nodules can be up to $500 \mathrm{~mm}$ in size and are difficult to recover in boreholes (Menkiti et al., 2015). As regards the Chalk, Bundy (2013) studied the particle size distributions of Chalk samples collected from several sites in the UK. The $D_{50}$ of these samples was found to range narrowly between 2 and $4 \mu \mathrm{m}$, which matched the longest dimension of individual coccolith plates as observed under an electron microscope. Bundy (2013) also studied the effect of milling on $D_{10}, D_{50}$ and $D_{90}$. There were only small changes in the $D_{10}$ and $D_{50}$ values as a result of milling, but $D_{90}$ reduced from around $100 \mu \mathrm{m}$ to $20 \mu \mathrm{m}$ when the milling duration was increased from $30 \mathrm{~s}$ to $14 \mathrm{~min}$, indicating a breakdown of the aggregated chalk particles. Breakdown of aggregated chalk particles also can occur in slurry-supported excavations due to the grinding action of the digging tools. Phillips (2016) reported the disaggregation rates of several British soils in relation to pipe jacking coupled with a slurry cutter head. Chalk was not included in that study programme and the disaggregation behaviour of chalk in bentonite slurry has been little reported to date, although contractors who have worked in Chalk will be aware of the risk of fines generation and will operate processes to minimise the risk so far as it is predictable. In addition to fines from Chalk, Thanet Sand also will contribute fines to excavation slurry.

\subsection{The fluid-supported excavation work}

The station box of the Woolwich station was approximately $260 \mathrm{~m}$ long and 23-29 $\mathrm{m}$ wide, with an internal depth of 12-18 m (Pennington, 2015). For construction of the station box, over 500 linear metres of diaphragm wall were required, all founded in the Chalk. The wall was constructed from 88 separate panels that were $24.5 \mathrm{~m}$ deep, $1 \mathrm{~m}$ wide and up to $7 \cdot 1 \mathrm{~m}$ long. A total of 51 bored piles with diameters of $1500 \mathrm{~mm}$ and $1800 \mathrm{~mm}$ and lengths ranging from 32-46 m were constructed to provide the necessary uplift resistance for the station box. In addition, the contractor installed lean-mix walls at the ends of the station box for the entrance and exit of the tunnel boring machine that was to pass through the box. A cement-bentonite cut-off wall was also installed midway along the box to enable dewatering of the site prior to the staged bulk excavation works. Altogether, about $20000 \mathrm{~m}^{3}$ of excavation was carried out under bentonite slurry. As the excavation had to pass through the Bullhead Bed, which posed a high risk for slurry loss, it was grouted prior to the works. A detailed discussion of the pre-excavation grouting can be found in Pennington (2015).

\section{Solids-separation equipment and procedures}

\subsection{Treatment process}

Figure 1 shows a diaphragm wall trench under excavation at the site. The excavation was carried out using clam shell grabs. It can be seen that the bentonite slurry in the trench was

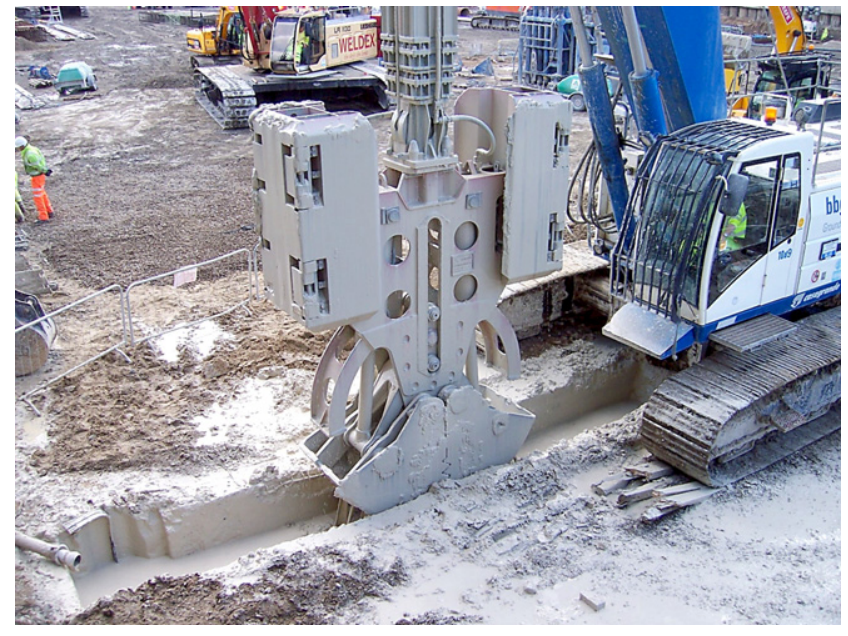

Figure 1. Diaphragm wall trench supported by bentonite fluid 
creamy white in colour, which was due to the suspended chalk particles in the slurry. Special attention was paid to the setup of the solids-separation plant so that the properties of the bentonite slurry could be maintained within the specified limits over the course of the project. Figure 2 shows a photograph of the plant, comprising a desander (SM250DP), a desilter (SU300DP), a second desander (Casagrande D14) and a centrifuge $(\mathrm{S} 3-01-\mathrm{H})$. The silos in the background were used to store fresh and treated bentonite slurry. Figure 3 shows a schematic diagram of the bentonite slurry mixing and treatment process. The bentonite used was a sodium-activated bentonite with the trade name Berkbent 163. This bentonite is commonly used in the UK for bored piling and diaphragm walling projects (Lam et al., 2015; Suckling et al., 2011). The bentonite slurry was mixed at a concentration of $40 \mathrm{~kg} / \mathrm{m}^{3}$ using local tap water pre-treated with sodium carbonate (soda ash) to precipitate calcium hardness. The density of the fresh slurry was $1.02 \mathrm{~g} / \mathrm{cm}^{3}$.

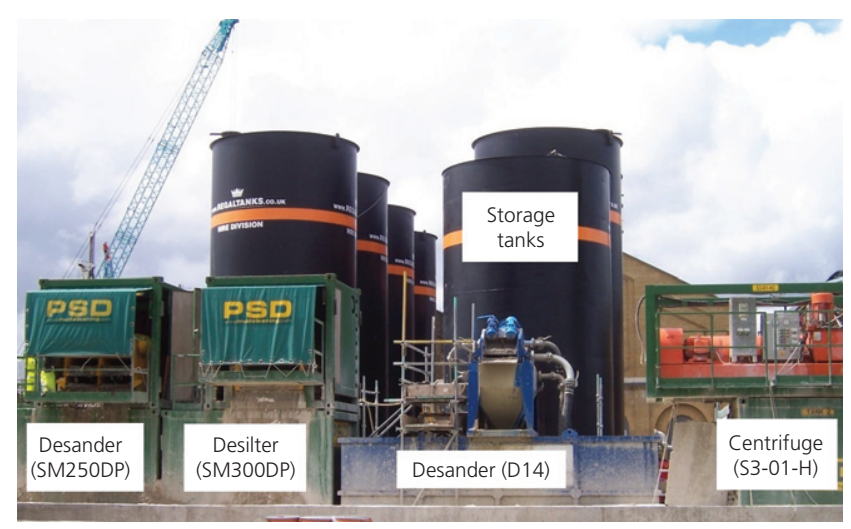

Figure 2. Solids-separation plant and storage tanks
After use in an excavation, the bentonite slurry was first sent to one or, if necessary, both of the desanders for removal of the coarse soil particles. Some of the slurry was then passed to a desilter for the removal of silt-sized soil particles. Due to its limited capacity, the desilter could not take the full flow from the two desanders when operating together. In addition, the centrifuge continuously processed some of the slurry to reduce the solids content. In this paper, this operating mode is referred to as the slurry thinning mode. In this mode, some but not all of the solids were removed from the slurry so that the underflow was a paste largely consisting of chalk with more minor amounts of bentonite and the overflow was a bentonite slurry with some residual chalk particles. After treatment, the bentonite slurry was sent to storage tanks.

\subsection{Details of the solids-separation equipment}

Descriptions of common solids-separation equipment can be found in textbooks on drilling and diaphragm walling (e.g. ASME SSC, 2005; Boyes, 1975, Verfel, 1989, Xanthakos, 1994). The equipment used in this project was as follows.

The SM250DP desander was provided by Pigott Shaft Drilling Ltd. Its rated capacity for recycled slurries is up to $250 \mathrm{~m}^{3} / \mathrm{h}$. It is designed to separate coarse and medium sands from recycled clay-based fluid, having a Marsh funnel time of up to $100 \mathrm{~s}$. In operation, the solids-laden slurry first passes through a coarse vibrating screen with an aperture size of $6 \mathrm{~mm}$. The screen underflow then passes to the recycle tank, from where it is pumped to three $250 \mathrm{~mm}$ (10 inch) dia. hydrocyclones (Figure 4(a)). The hydrocyclones concentrate the coarse particles into the underflow, which falls onto a vibrating dewatering screen with an aperture size of $500 \mu \mathrm{m}$. The dewatered solids are discharged at the front of the screen deck (Figure 4(b)). The fluid passing through the screen drops back

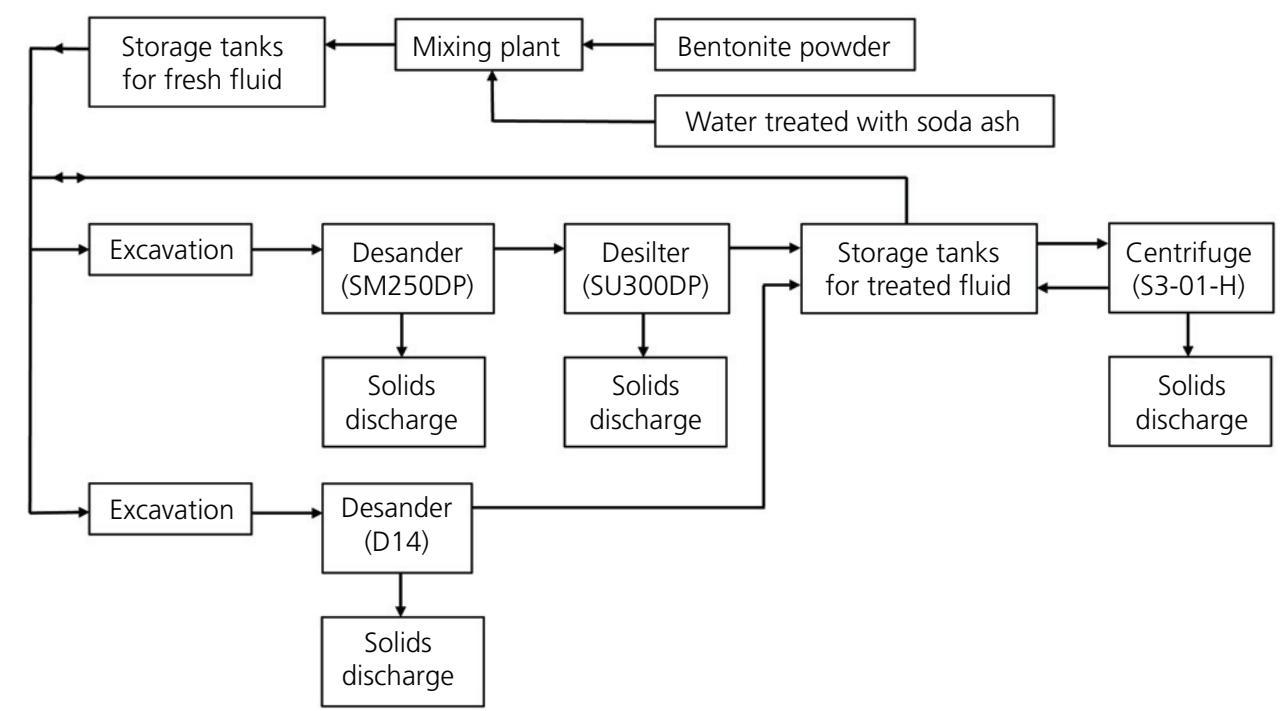

Figure 3. Schematic diagram of bentonite mixing and treatment process 
Geotechnical Engineering

Volume 171 Issue GE6
Treatment of bentonite fluid for

excavation into Chalk

Lam, Jefferis and Suckling

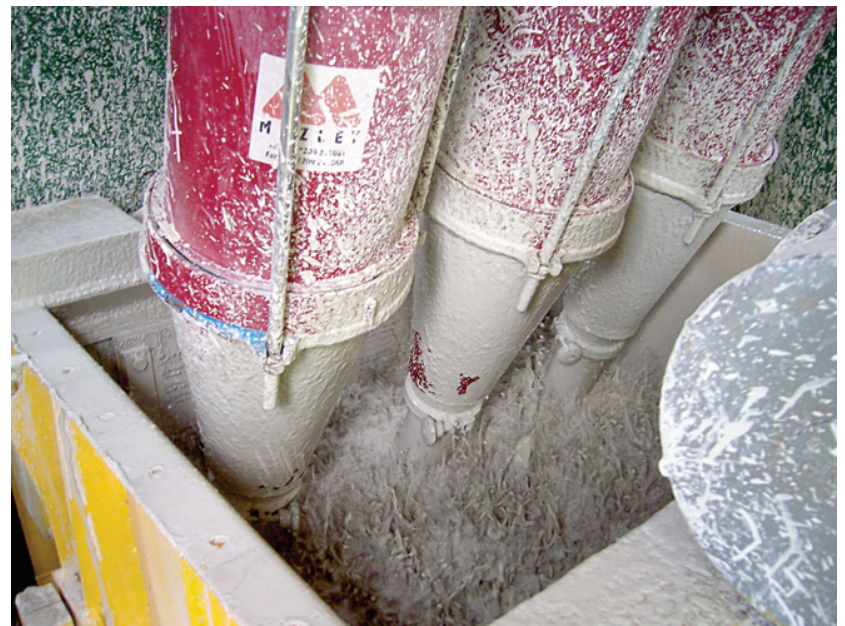

(a)

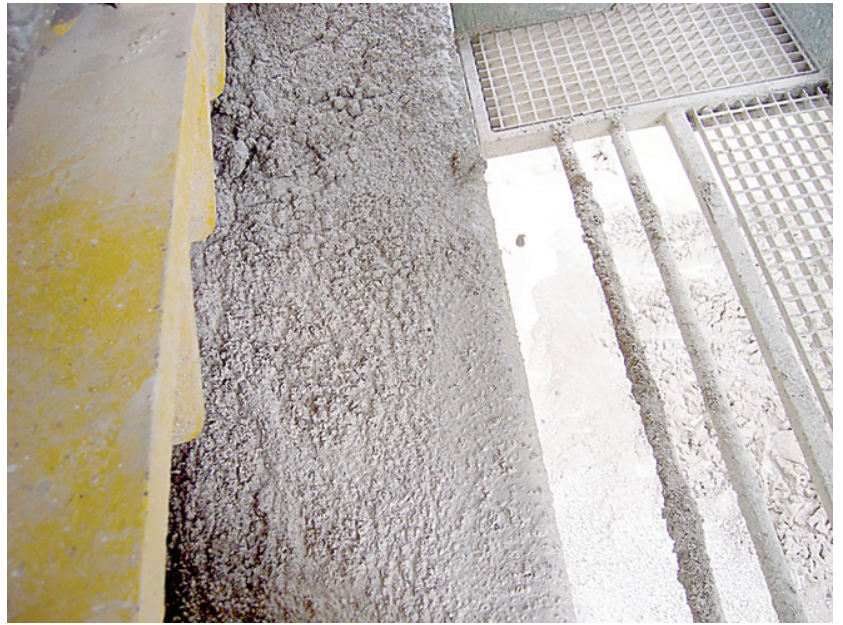

(b)

Figure 4. Desander SM250DP: (a) hydrocyclones; (b) dewatered solids

into the recycle tank. The overflow from the hydrocyclones, which will still contain silt- and clay-sized particles and a minor amount of coarser material, passes to a treated slurry tank. From this tank the slurry is either pumped to the desilter or flows back to the recycle tank for recycling through the hydrocyclones.

The Casagrande D14 desander has a flow capacity of $140 \mathrm{~m}^{3} / \mathrm{h}$. It has a different layout to the SM250DP desander but operates in a similar way. In operation, the solids-laden fluid first passes through a vibrating coarse screen with an aperture size of $8 \mathrm{~mm}$. From the screen, the fluid falls into a tank, from where it is pumped to an obliquely mounted $420 \mathrm{~mm}$ dia. hydrocyclone (Figure 5(a)); note that the centrifugal forces in a hydrocyclone are sufficiently high that its orientation to the vertical has no impact on its performance. The coarser solids are concentrated and discharged as the

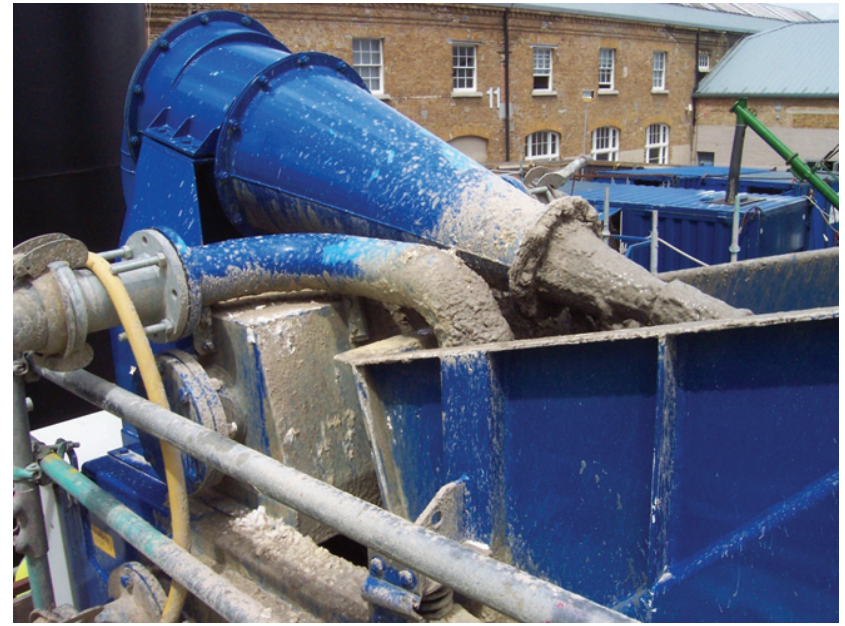

(a)

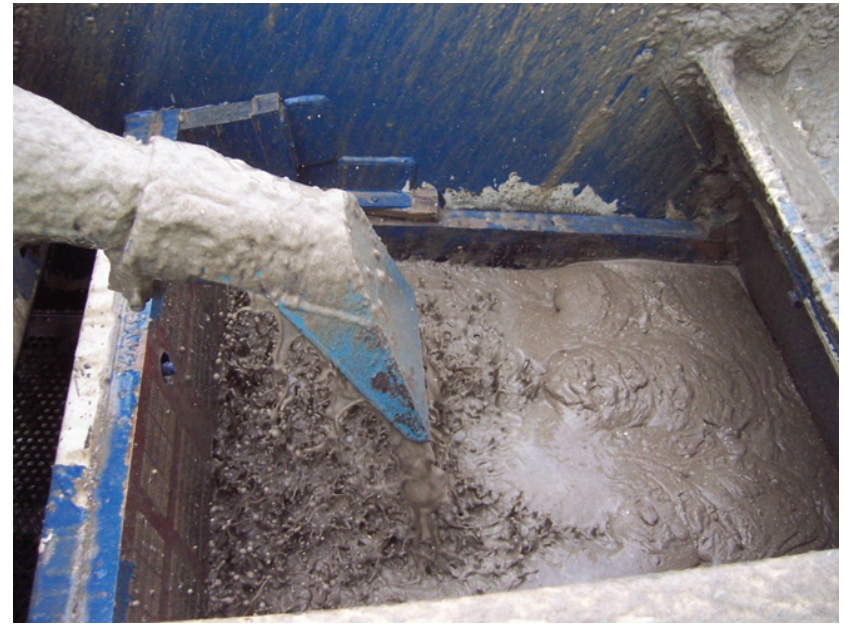

(b)

Figure 5. Desander D14: (a) hydrocyclone; (b) hydrocyclone underflow

underflow onto a vibrating dewatering screen (Figure 5(b)). After dewatering, the solids are discharged at the front of the unit. The overflow from the hydrocyclone is then sent to storage tanks or the desilter.

The SU300DP desilter was supplied by Pigott Shaft Drilling Ltd. It has a flow capacity of up to $300 \mathrm{~m}^{3} / \mathrm{h}$. As its name suggests, it is designed to remove silt-sized soil particles from the slurry after treatment in one of the primary desanders. The flow circuit of the desilter is very similar to that of the SM250DP desander. The principal difference is that the hydrocyclones are of smaller diameter and finer dewatering screens are used. Hydrocyclones with a smaller diameter are used as the cut point of a hydrocyclone reduces with its diameter. However, a reduced diameter also reduces the throughput per hydrocyclone and increases the risk of blockages. Typically, the minimum hydrocyclone diameter for excavation slurries is 
about $100 \mathrm{~mm}$ and long-bodied hydrocyclones are used as these have a lower cut point than shorter hydrocyclones of the same diameter. In operation, the desanded slurry is first pumped from the unit's recycled fluid tank to 12 hydrocyclones of $125 \mathrm{~mm}$ (5 inch) diameter (Figure 6(a)). The soil particles in the fluid are concentrated in the underflow and discharged onto two decks of vibrating dewatering screens. For this project, screens with openings of $300 \mu \mathrm{m}$ and $106 \mu \mathrm{m}$ were used, with corresponding American Petroleum Institute (API) screen numbers of API 50 and API 140, respectively (API, 2014). The solids that are separated by the screens are discharged at the front of the unit (Figure 6(b)) while the slurry

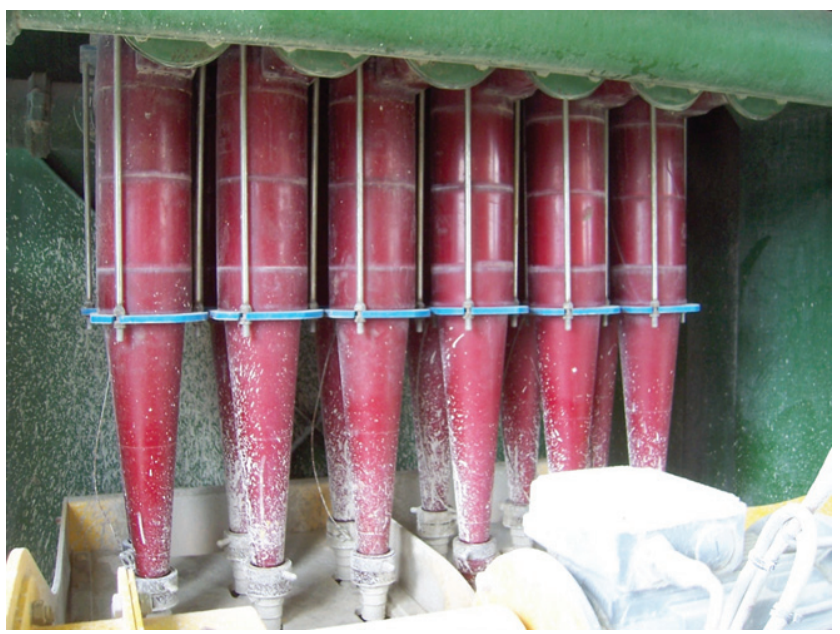

(a)

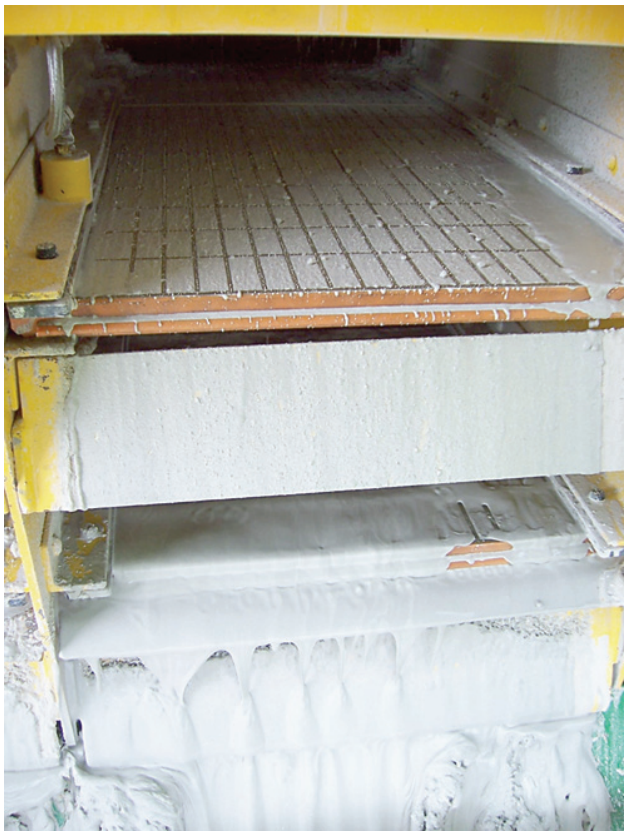

(b)

Figure 6. Desilter SU300DP: (a) hydrocyclones; (b) vibrating dewatering screens passing through screens returns to the recycled fluid tank. The overflow from the hydrocyclones is either pumped to the storage tanks or flows back to the recycle tank for recycling through the hydrocyclones.

The centrifuge (model S3-01-H) was also supplied by Pigott Shaft Drilling Ltd. It comprises a horizontal chamber, known as a bowl, of diameter $530 \mathrm{~mm}$ and length $2270 \mathrm{~mm}$. The bowl can rotate at speeds of up to $2200 \mathrm{rpm}$ and can develop centrifugal acceleration up to $1425 \mathrm{~g}$. Slurry for treatment is pumped into the rotating bowl and the soil particles migrate to the wall due to the high centrifugal acceleration. Inside the bowl, there is a scroll conveyor rotating at a slightly higher speed than the bowl so that it continuously pushes the settled solids to the discharge outlet, while the treated fluid is discharged to a storage tank below the centrifuge (Figure 7). In this project, the centrifuge was used to treat desilted bentonite slurry (slurry after passage through the desilter) both for reuse and for final disposal. For the first purpose, where the centrifuge was required only to reduce the solids content of the slurry, the bowl speed was $1250 \mathrm{rpm}$ and the scroll speed was $16 \mathrm{rpm}$ higher. This setup allowed the recycled fluid to be treated at a rate of around $6 \mathrm{~m}^{3} / \mathrm{h}$. For the second purpose (i.e. separation prior to disposal), the centrifuge was used to separate the unwanted bentonite slurry into an underflow paste and a near-clear water overflow. For this, a higher bowl speed and a lower flow rate were necessary; the bowl speed was increased to $1650 \mathrm{rpm}$ and the scroll was operated at $14 \mathrm{rpm}$ faster than the bowl. The fluid treatment rate was slightly lower at $5 \mathrm{~m}^{3} / \mathrm{h}$. These speed settings generally follow the advice of the

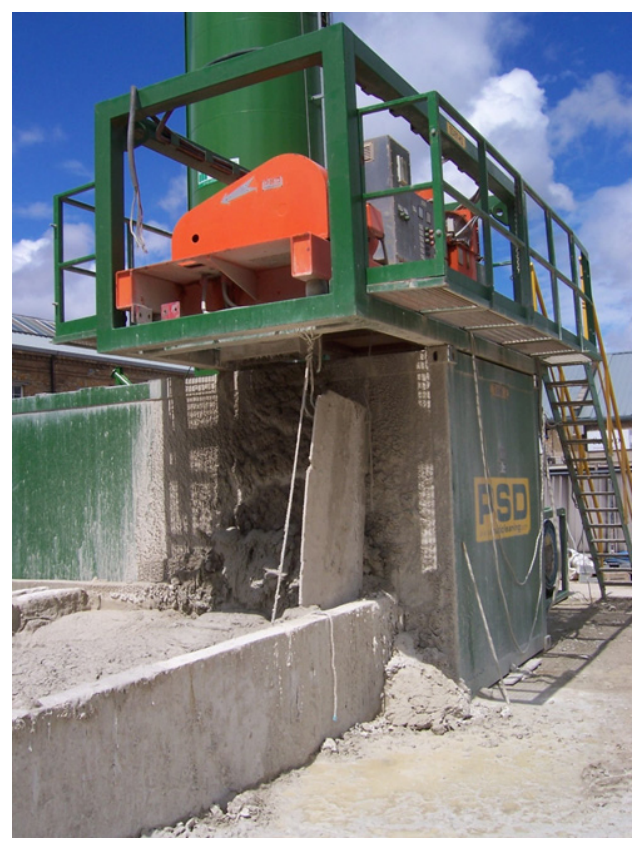

Figure 7. Centrifuge $\mathrm{S} 3-01-\mathrm{H}$ and solids discharge at the front 
Geotechnical Engineering

Volume 171 Issue GE6
Treatment of bentonite fluid for

excavation into Chalk

Lam, Jefferis and Suckling centrifuge supplier: for the removal of very fine solids, a high bowl speed is needed and the retention time for solids within the centrifuge is increased by running the scroll at a lower differential speed. It may be noted that the rate of $5-6 \mathrm{~m}^{3} / \mathrm{h}$ is very much lower than the return flow rate from a diaphragm wall excavation during concreting and thus the centrifuge was operated off-line from the main slurry circuit.

\section{Fluid treatment for reuse}

\subsection{Removal of solids}

The effectiveness of the fluid treatment process was first evaluated by studying the behaviour of the desander, desilter and centrifuge on a single occasion, examining the sizes of the soil particles in the treated fluids. To this end, samples of the treated slurries and solid discharges were taken from the desander (SM250DP), the desilter (SU300DP) and the centrifuge (S3-01-H) operating in slurry thinning mode. The samples were oven dried and then examined under a scanning electron microscope (Hitachi S-3400N) with a magnification of $50 \times$. Figures 8 and 9 show electron micrographs of the dried treated fluids (overflows) and solid discharges, respectively, from the three pieces of equipment. In these micrographs, the particles have different levels of brightness. This is due to the build-up of excess electrons on some particles during the imaging process and should not affect the interpretation of results. Together, Figures 8 and 9 show that the particle sizes in the treated fluids generally decreased with increasing treatment. It is interesting to note that the soil particles in the liquid discharges could be larger than the aperture sizes of the dewatering screens of the associated equipment. For example, the aperture sizes of the coarse and fine dewatering screens on the SU300DP desilter were $300 \mu \mathrm{m}$ (upper screen) and $106 \mu \mathrm{m}$ (lower screen) but the soil particles in the liquid discharge had dimensions up to about $300 \mu \mathrm{m}$ (Figure 8(b)). At first sight, this may seem surprising but could be due to the following

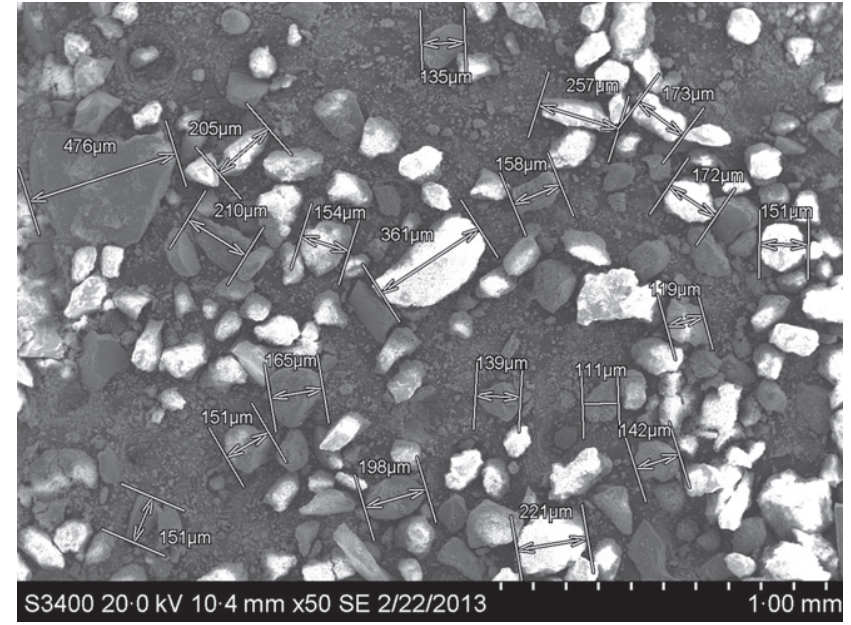

(a)

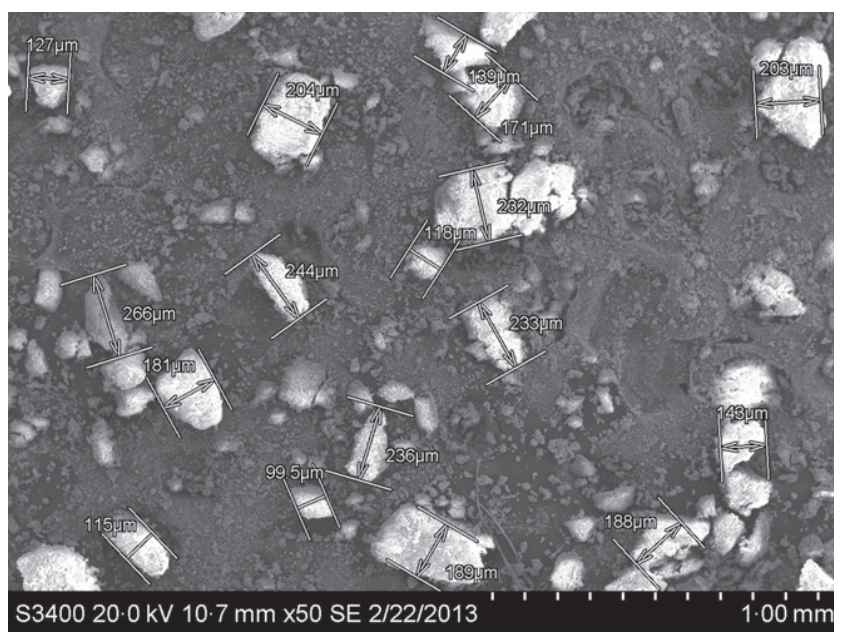

(b)

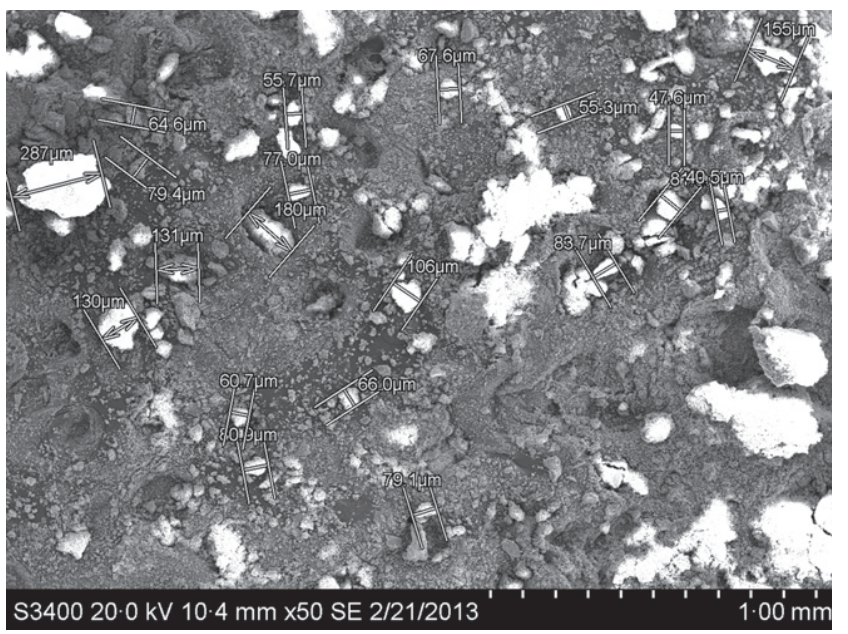

(c)

Figure 8. Electron micrographs of dried treated fluids from: (a) desander SM250DP; (b) desilter SU300DP; (c) centrifuge S3-01-H 


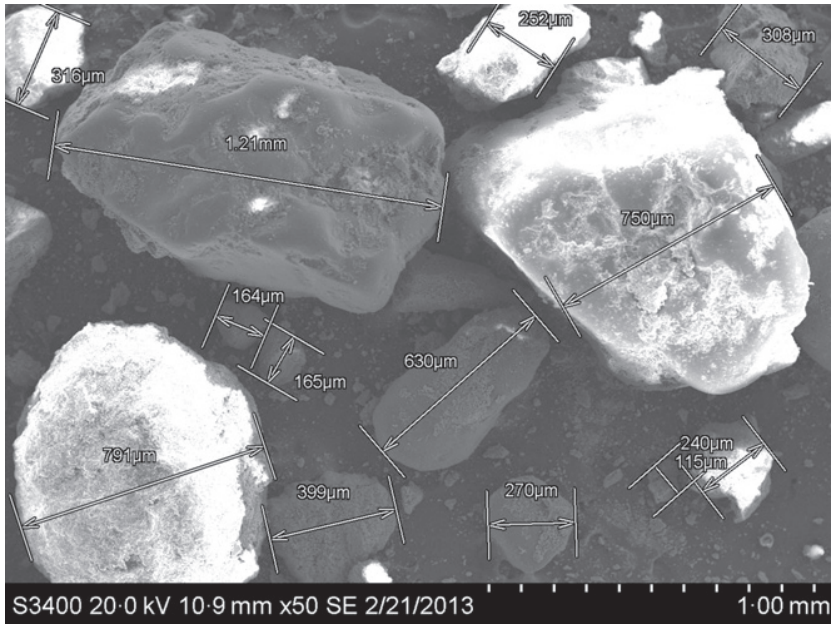

(a)

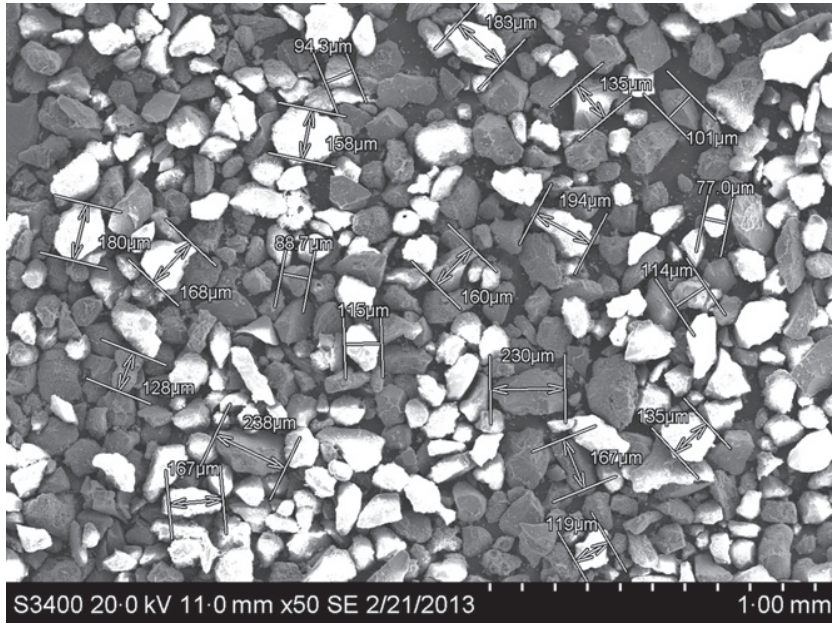

(b)

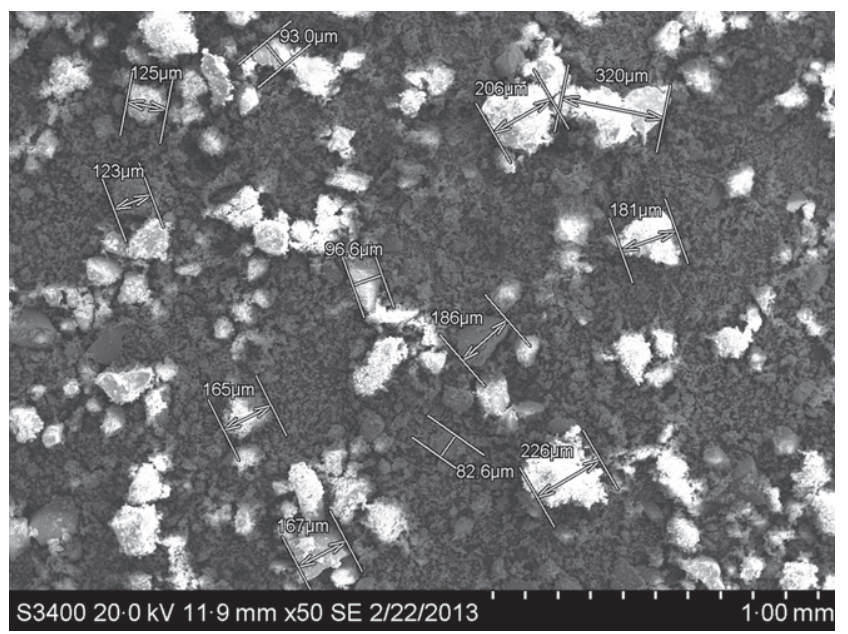

(c)

Figure 9. Electron micrographs of dried solid discharges from: (a) desander SM250DP; (b) desilter SU300DP; (c) centrifuge S3-01-H

three reasons: (a) As described previously, the liquid discharge from the desilter is from the overflow of the hydrocyclones. A hydrocyclone does not have a sharp cut like a perfect screen and, statistically, some coarser materials will report to the overflow, especially when the solids content (or density) of the feed slurry, and thus also the slurry viscosity, is high; hence the use of a recycle on the hydrocyclone unit which acts to minimise the amount of oversized particles in the overflow. (b) Dewatering screens often have rectangular slots so that the maximum particle dimension can be greater than the minimum screen opening. (c) Screens are easily damaged, in which case some oversize particles can slip through holes.

Further information on plant performance was obtained from moisture content and density measurements on a set of samples of treated fluids. These samples showed moisture contents of $287 \%, 442 \%$ and $538 \%$, respectively, for the treated fluids from the desander, desilter and the centrifuge in slurry thinning mode, corresponding to solids contents (defined as weight of solids/total weight) of $26 \%, 18 \%$ and $16 \%$. The associated measured fluid densities were 1.20, 1.14 and $1 \cdot 11 \mathrm{~g} / \mathrm{cm}^{3}$, respectively. Thus, at the time of sampling, the combination of desander plus desilter was able to maintain the treated slurry to within the specified limit of $1.25 \mathrm{~g} / \mathrm{cm}^{3}$ for slurry for reuse. On other occasions, it was necessary to blend the treated slurry with fresh slurry and overflow from the centrifuge to maintain its density below the $1.25 \mathrm{~g} / \mathrm{cm}^{3}$ limit.

\subsection{Properties of treated fluids at different locations}

The effectiveness of the solids-separation process was also assessed by measuring the properties of the treated bentonite slurry at different sampling locations in the fluid circuit at a particular time; these samples were different from those discussed in the previous section. As an example of the slurry properties, Table 1 summarises the properties of samples taken from digging slurry from the excavation for a pile, after 
Table 1. Properties of bentonite fluids at three sampling points on one sampling occasion and control values from BS EN 1538:2010 (BSI, 2010)

\begin{tabular}{|c|c|c|c|c|c|c|}
\hline \multirow[b]{2}{*}{ Property } & \multicolumn{4}{|c|}{ Measured value } & \multicolumn{2}{|c|}{$\begin{array}{l}\text { Control values from } \\
\text { BS EN 1538:2010 }\end{array}$} \\
\hline & $\begin{array}{l}\text { Digging } \\
\text { fluid }\end{array}$ & $\begin{array}{l}\text { After desander and } \\
\text { desilter treatment }\end{array}$ & $\begin{array}{c}\text { After decanting } \\
\text { centrifuge treatment }\end{array}$ & $\begin{array}{l}\text { Freshly } \\
\text { mixed }\end{array}$ & $\begin{array}{l}\text { Ready for } \\
\text { reuse }\end{array}$ & $\begin{array}{l}\text { Freshly } \\
\text { mixed }\end{array}$ \\
\hline Density: $\mathrm{g} / \mathrm{cm}^{3}$ & $1 \cdot 34$ & $1 \cdot 24$ & $1 \cdot 14$ & 1.025 & $<1.25$ & $<1 \cdot 10$ \\
\hline Fluid loss volume: $\mathrm{ml}$ & 33 & 27 & 24 & 21 & $<50$ & $<30$ \\
\hline Filter cake thickness: $\mathrm{mm}$ & 6 & 3 & 1.5 & 1 & $<6$ & $<3$ \\
\hline Marsh funnel time: $\mathrm{s}$ & 47 & 36 & 34 & 34 & $32-60$ & $32-50$ \\
\hline $\mathrm{pH}$ & $11 \cdot 2$ & $10 \cdot 6$ & $10 \cdot 7$ & $10 \cdot 4$ & $7-12$ & $7-11$ \\
\hline
\end{tabular}

desander and desilter treatment, after centrifuge treatment and from the fresh slurry mixer. The measured properties were fluid density, Marsh funnel time, $\mathrm{pH}$, fluid loss volume and filter cake thickness. These properties were measured according to the procedures given in FPS (2006) except that density was measured using a pycnometer instead of the conventional mud balance for improved accuracy (Jefferis and Lam, 2017; Lam, 2016). The control values given in BS EN 1538:2010 (BSI, 2010) for diaphragm walling are also included in Table 1 for comparison. BS EN 1538:2010 does not include any parameters for digging slurry. However, a possible upper density limit of $1.35 \mathrm{~g} / \mathrm{cm}^{3}$ is given in ICE (2017) for digging slurry. Few tests were undertaken on the digging slurry on site as they were not required.

Table 1 shows that the slurry density was as high as $1.34 \mathrm{~g} / \mathrm{cm}^{3}$, which is a relatively challenging density for the soil-slurry separation plant. However, desanding and desilting reduced the density of the digging slurry to $1.24 \mathrm{~g} / \mathrm{cm}^{3}$, which is just within the specification given in BS EN 1538:2010, which sets an upper limit of $1.25 \mathrm{~g} / \mathrm{cm}^{3}$. The centrifuge in the slurry thinning mode (removing some but not all solids) further reduced the slurry density to $1.14 \mathrm{~g} / \mathrm{cm}^{3}$, which is comfortably within the specification for the works. Ultimately, the slurry for reuse will have been a mix of desanded and desilted slurry, centrifuge-treated slurry and fresh slurry to make up for slurry losses to the ground and with the excavated soil. As the bulk fluid loss to the ground at this site was higher than typical for other areas of London, the volume of make-up fresh slurry was significant despite the prior grouting of the Bullhead Bed.

Typically, in clays and silty soils, the $\mathrm{pH}$ of bentonite slurry drops in use. It is interesting to note that the $\mathrm{pH}$ of the digging slurry was 11.2 compared with $10 \cdot 4$ for the fresh slurry. This increase in $\mathrm{pH}$ is unlikely to have been due to the chalk particles but rather to digging through the cement-grouted Bullhead Bed. In addition to raising the $\mathrm{pH}$ of the slurry, cement will flocculate bentonite particles, resulting in an increase in viscosity and fluid loss volume (FPS, 2006); these effects were also observed in this project (Table 1). Sodium bicarbonate $\left(\mathrm{NaHCO}_{3}\right)$ can be used to reduce the $\mathrm{pH}$ of contaminated slurry, but this was not necessary in this project. It may be noted that chalk has no chemical effect on bentonite. Indeed, a sodium-activated bentonite will contain about $4 \%$ calcium carbonate (chalk) precipitated during the original conversion process from calcium bentonite to sodium bentonite.

\subsection{Effects of density on fluid properties}

To investigate the effects of slurry density on other fluid properties, Figures 10-14 respectively show plots of $\mathrm{pH}$, fluid loss, Marsh funnel time, apparent viscosity and gel strength of fresh and treated fluids against density. The apparent viscosity and gel strength were determined with a direct-indicating viscometer (FPS, 2006; Lam and Jefferis, 2014, 2015). These results were obtained by the contractor's field technicians during the course of the project as part of the quality control work.

The increase in $\mathrm{pH}$ with density (Figure 10) was probably due to cement contamination as previously discussed - the higher density slurries had higher excavated soil contents and thus potentially higher degrees of cement contamination from the grouting of the Bullhead Bed. At this site, the fluid loss, which

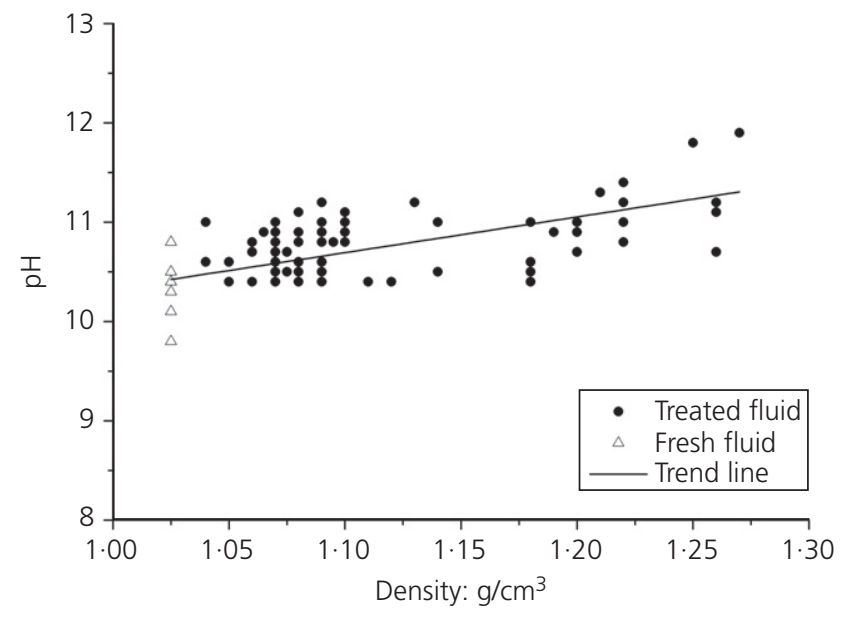

Figure 10. Effect of fluid density on $\mathrm{pH}$ 


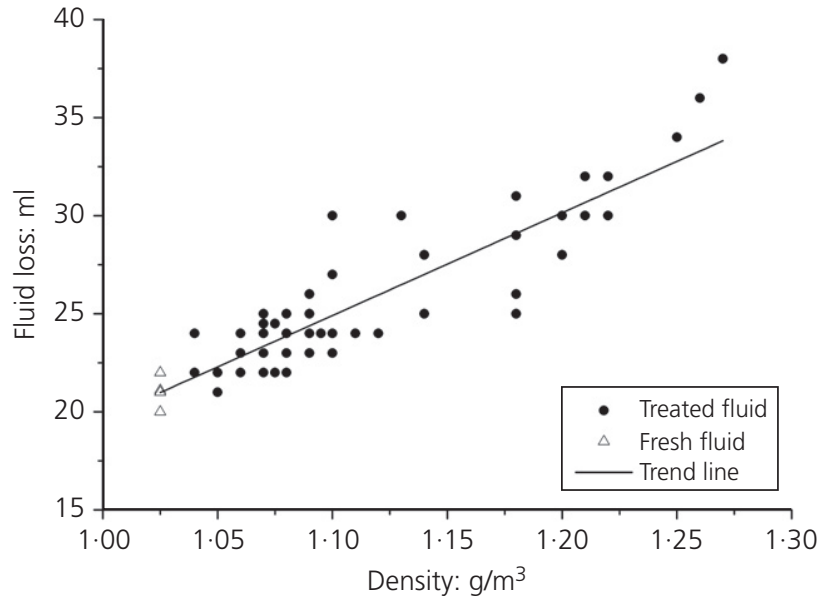

Figure 11. Effect of fluid density on fluid loss

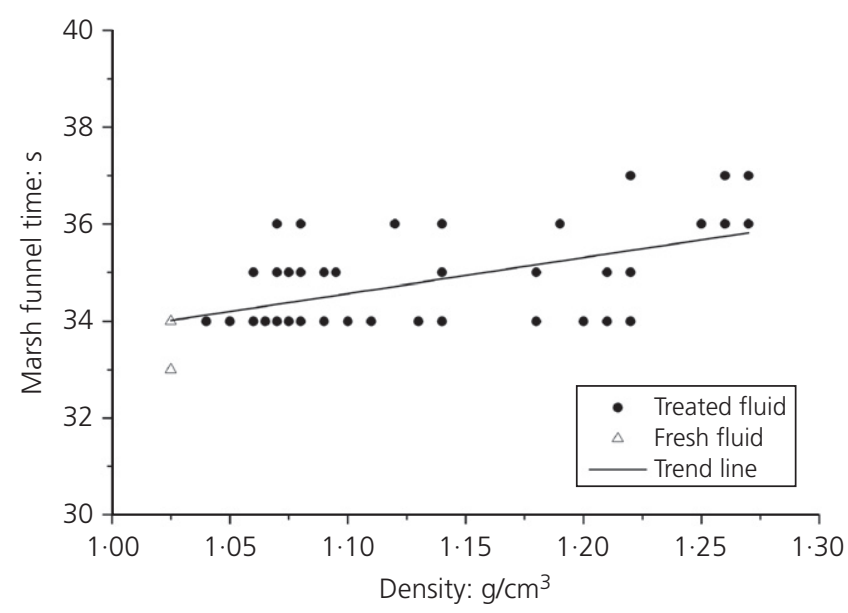

Figure 12. Effect of fluid density on Marsh funnel time

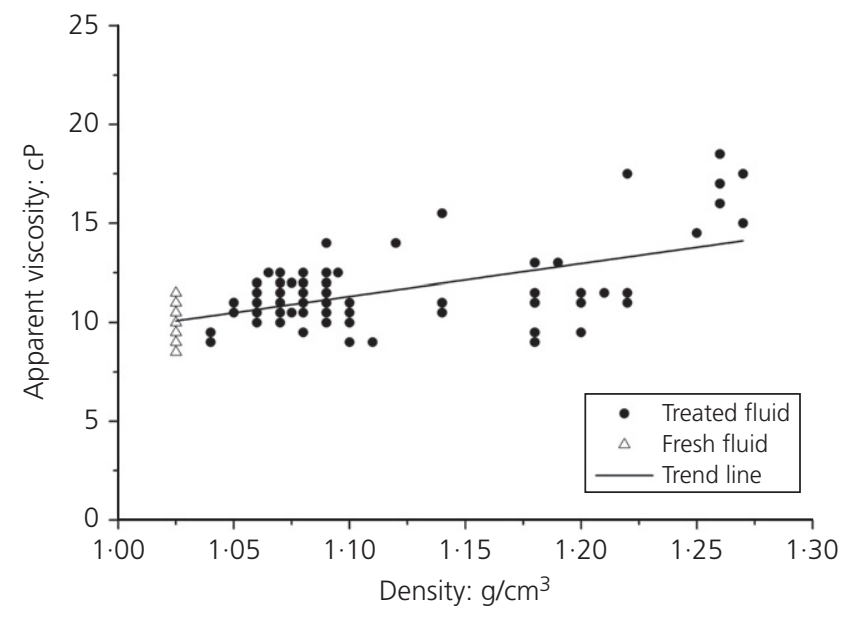

Figure 13. Effect of fluid density on apparent viscosity

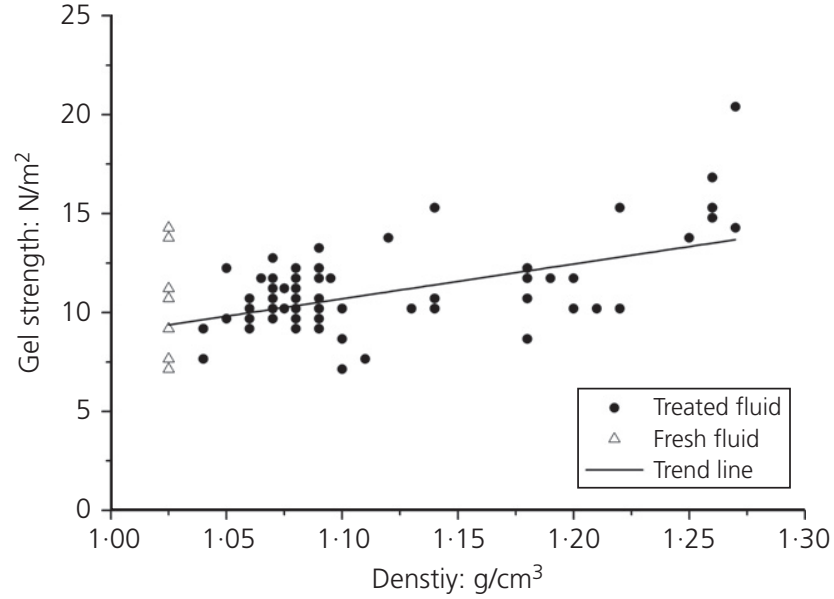

Figure 14. Effect of fluid density on gel strength

was measured in a standard API cell (FPS, 2006), showed a trend of increasing loss with increasing density (Figure 11). However, data from other sites with Chalk have shown an inverse trend (i.e. decreasing fluid loss with increasing density). It would therefore seem that the cement from the grouted Bullhead Bed had a greater impact than the fines. The Marsh funnel data (Figure 12) showed a very narrow range of results, from 34 to $37 \mathrm{~s}$. However, since the Marsh funnel test results were reported only to the nearest second, it would be unwise to suggest any correlation with slurry density. The apparent viscosity and gel strength showed considerable scatter and weak trends of increases with density (Figures 13 and 14).

Overall, the findings were very much as expected. Slurry density in excess of the fresh slurry density is an indicator of the amount of excavated soil (and associated cement grout on this site) in the slurry. For example, a slurry with a density of $1.25 \mathrm{~g} / \mathrm{cm}^{3}$ will contain about $395 \mathrm{~kg} / \mathrm{m}^{3}$ solids (assuming the solids are predominantly chalk with a density of $2.71 \mathrm{~g} / \mathrm{cm}^{3}$ ), whereas the fresh bentonite slurry will have contained only $40 \mathrm{~kg} / \mathrm{m}^{3}$ bentonite. Reducing slurry density after use will tend to return slurry properties to those of the fresh slurry but some non-bentonite fines will remain within the slurry. The concentration of bentonite by weight of water will also reduce with use as a result of the water released from the excavated soil (Jefferis, 2014). These effects will be partially compensated by fresh slurry added to the fluid circuit to make up for bulk fluid losses to the ground and with the excavated soil. Cement contamination will continue to impact on the slurry, tending to increase its gel strength, and this in turn will increase its solidsholding capacity - an adverse effect.

\section{Fluid treatment for disposal}

\subsection{Methodology}

In addition to treating bentonite slurry for reuse, the centrifuge was used to treat the unwanted bentonite slurry for disposal at 
the end of the project. As previously described, the centrifuge was operated at a slightly higher bowl speed and a lower differential speed between the scroll and bowl than when operated in slurry thinning mode for slurry treatment prior to reuse. To improve the efficiency of solid-liquid separation, calcium chloride as a coagulant and an organic flocculant (Polyfloc 190CG) were added to the slurry prior to centrifugation. The supplier states that Polyfloc 190CG is an anionic polyacrylamide with a high molecular weight, which can be used in wastewater treatment. The divalent calcium cations compress the electrical double layer around the bentonite particles, so promoting aggregation of the particles. The charged longchain polymer molecules can gather the destabilised bentonite particles together to form larger flocs, which settle more rapidly than individual particles. When used, the polymer and calcium chloride were first mixed with potable water at concentrations of $0.85 \mathrm{~kg} / \mathrm{m}^{3}$ and $6.3 \mathrm{~kg} / \mathrm{m}^{3}$, respectively, in separate mixing tanks. They were then added to the bentonite slurry in approximately equal amounts prior to centrifuging. Phillips (2016) gives details of procedures to optimise the flocculant dose for centrifugation.

\subsection{Effectiveness of treatment}

The effectiveness of the solid-liquid separation process was evident on site as the centrate was near-clear water and the solid discharge had a soft paste-like consistency. For this project, the contractor had obtained prior consent from the local water authority to discharge the centrate directly to the site foul sewer. To confirm that the centrate complied with the discharge consent, chemical analyses were carried out by a commercial laboratory on two separate samples of the centrate. Table 2 summarises the consent limits and the associated test results. It can be seen that the centrate had the required low solids content. Of the other parameters, the chloride content was relatively high as a result of the use of calcium chloride as a coagulant.

The properties of dewatered bentonite sludge are also important since the disposal costs of liquid wastes are much higher than those for solid wastes. If dewatered bentonite sludge is classified as a solid waste, it can be disposed of with other soil arisings from the site by conventional means. According to
Defra (2010), liquid waste is defined as any waste that almost instantaneously flows into an indentation void made in the surface of the waste, or any waste load containing a free-draining liquid substance in excess of 2501 or $10 \%$ of the load volume, whichever represents the lesser amount. The first of these interpretations can be used to distinguish between liquid and sludge. A waste that flows only slowly, rather than nearly instantaneously, into an indentation void will be a sludge and a solid for waste regulation purposes. Figure 15 shows a photograph of the dewatered bentonite sludge. It can be seen that the sludge did not flow into an indentation on the surface made with a palette knife. Furthermore, the chalk-bentonite sludge did not release any free-flowing liquid.

\section{Conclusions}

The key findings of the slurry data and the soil-slurry separation plant from this study can be summarised as follows.

(a) The solids-separation equipment used was effective in removing soil particles from the recycled bentonite slurry and thus reducing its density. However, the slurry after treatment in the desander and desilter could still contain significant amounts of chalk. Even after treatment in the desanders and desilter, slurry densities could be up to $1.27 \mathrm{~g} / \mathrm{cm}^{3}$, which was too high for reuse without further management.

(b) As expected, although not always appreciated, the slurry after treatment contained minor amounts of particles coarser than the aperture sizes of the finest dewatering screen. Among other reasons, this is because a hydrocyclone does not produce a sharp cut as with a perfect sieve but rather its behaviour can be described by a size-distributed efficiency curve where the $D_{95}$ may be several times the cut size for $50 \%$ removal.

(c) The use of a centrifuge in slurry thinning mode (i.e. the removal of some but not all the solids) was essential to prevent solids build-up in the slurry circuit on this project where disintegration of the chalk during excavation led to the release of fine particles that were finer than could be sufficiently removed by the desilter. The fresh make-up slurry required to compensate for bulk losses helped to reduce the recycled slurry density and keep it within

Table 2. Results of chemical analysis of centrate

\begin{tabular}{lrrr} 
Property & Consent limit & Sample 1 & Sample 2 \\
\hline pH & $6-11$ & $8 \cdot 3$ & $8 \cdot 6$ \\
Suspended solids: mg/l & $<2000$ & 38 & 111 \\
Rapidly settleable solids: $\mathrm{mg} / \mathrm{l}$ & $<100$ & 6 & 22 \\
Settleable solids: $\mathrm{mg} / \mathrm{l}$ & $<1000$ & 7 & 81 \\
Chemical oxygen demand: $\mathrm{mg} / \mathrm{l}$ & $<1000$ & 517 & 315 \\
Chloride content: $\mathrm{mg} / \mathrm{l}$ & $<1500$ & 1292 & 913 \\
Sulphate content $(\mathrm{as} \mathrm{SO}$ ): $\mathrm{mg} / \mathrm{l}$ & $<1800$ & 230 & 300
\end{tabular}

Note: Analyses were also undertaken for chromium, copper, lead, nickel, iron, zinc, unsaponifiable oil and available chlorine. The results were all well below the consent limits 


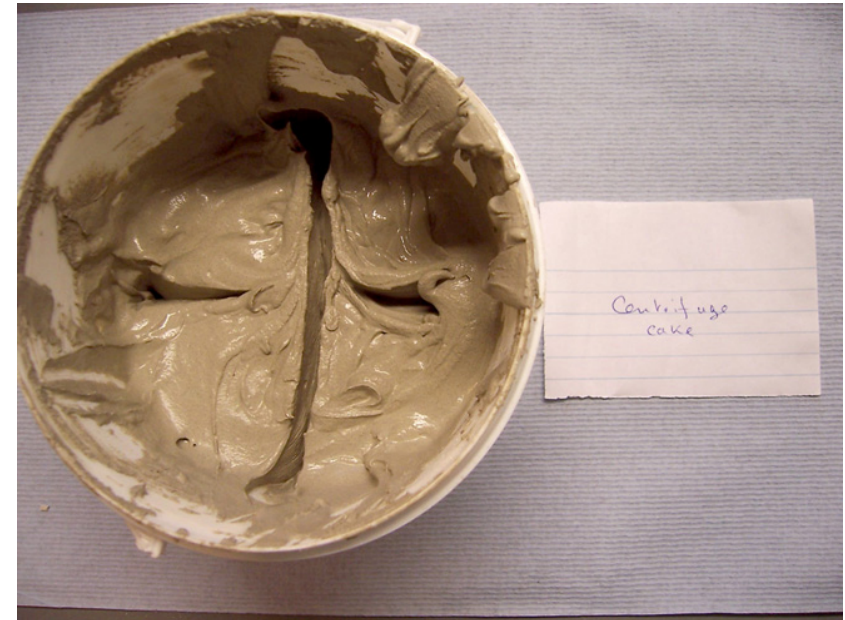

Figure 15. Dewatered bentonite sludge

specification. It is perhaps instructive to note that the third edition of the ICE Specification for Piling and Embedded Retaining Walls (ICE, 2017), which was published after completion of this project, suggests an upper density limit of $1.08 \mathrm{~g} / \mathrm{cm}^{3}$ for reuse. If such a density had been necessary on site, the centrifuge capacity would have had to be increased by using either more or larger centrifuges, or both.

(d) The density of bentonite slurry in excess of that of fresh slurry is a direct indicator of the mass of excavated soil suspended in the slurry. Other properties such as fluid loss, apparent viscosity and gel strength often show some correlations with density but the trends depend very much on the nature of the soil dispersed in the slurry. Also, on this site, the slurry behaviour will have been influenced by cement from the grouted Bullhead Bed.

(e) The apparent correlation of $\mathrm{pH}$ with density at this site was probably due to the grouting works carried out in the Bullhead Bed prior to the excavation works. The higher density of the slurry, the greater was its excavated soil content and thus the greater was the chance that it may contain grouted material from the Bullhead Bed. On sites without grouting, a reduction in $\mathrm{pH}$ with density or no correlation is more typical.

( $f$ ) At the end of the project, the centrifuge was successfully used to separate the unwanted bentonite slurry into material that was classified as solid waste for disposal purposes and water that met the criteria for direct disposal to a foul sewer. This avoided any requirement to tanker liquid waste off site for treatment by others prior to disposal.

\section{Acknowledgements}

The first author was funded by the UK Engineering and Physical Sciences Research Council under the Knowledge
Transfer Secondment scheme (grant reference EP/H50026X/1) whilst carrying out research on the applications of excavationsupport fluids at the University of Oxford, including the sitework for the case history discussed in this paper. Balfour Beatty Ground Engineering permitted access to the Woolwich site and provided technical support. The scanning electron micrographs were taken with the assistance of Ms P. K. Wong of the University of Macau.

\section{REFERENCES}

AASHTO (American Association of State Highway and Transportation Officials) (2017) LRFD Bridge Construction Specifications, 4th edn. AASHTO, Washington, DC, USA.

API (American Petroleum Institute) (2014) Recommended Practice on Drilling Fluid Systems Evaluation. API Recommended Practice $13 C, 5$ th edn. API, Washington, DC, USA.

ASME SSC (ASME Shale Shaker Committee) (2005) Drilling Fluids Processing Handbook. Gulf Professional Publishing, Oxford, UK. Boyes RGH (1975) Structural and Cut-off Diaphragm Walls. Applied Science Publishers, London, UK.

BSI (2010) BS EN 1538:2010: Execution of special geotechnical works - diaphragm walls. BSI, London, UK.

Bundy SPS (2013) Geotechnical Properties of Chalk Putties. PhD thesis, University of Portsmouth, Portsmouth, UK.

Cowie HF and Crawley JD (1989) The use of a reverse circulation diaphragm walling technique to form a plastic cut-off wall around Sizewell B Power Station. Piling and Deep Foundations: Proceedings of the 3rd International Conference on Piling and Deep Foundations, London (Burland JB and Mitchell JM (eds)). Balkema, Rotterdam, the Netherlands, pp. 193-198.

Defra (Department for Environment, Food and Rural Affairs) (2010) Environmental Permitting Guidance - The Landfill Directive. Defra, London, UK.

FPS (Federation of Piling Specialists) (1975) Specification for cast in place piles formed under bentonite suspension. Ground Engineering 8(2): 50-52.

FPS (1977) Modifications to specification for cast in place concrete diaphragm walling (published 1973) \& specification for cast in place piles formed under bentonite suspension (published 1975). Ground Engineering 10(8): 45.

FPS (1985) Specification for cast in place piles formed under bentonite suspension. Ground Engineering 18(4): 11-15.

FPS (2000) Bentonite Support Fluids in Civil Engineering. FPS, Bromley, UK.

FPS (2006) Bentonite Support Fluids in Civil Engineering, 2nd edn. FPS, Bromley, UK.

GEO (Geotechnical Engineering Office) (2006) Foundation Design and Construction. GEO, Civil Engineering and Development Department, the Government of the Hong Kong Special Administrative Region, Hong Kong, China, Publication No. 1/2006.

Hindmarch JA, Griffiths AL, Officer AK and Wittneben G (2008) Durban Harbour tunnel - first use of a slurry tunnel boring machine in South Africa. Journal of the South African Institute of Mining and Metallurgy 108(1): 1-8.

ICE (Institution of Civil Engineers) (1996) ICE Specification for Piling and Embedded Retaining Walls. Thomas Telford, London, UK.

ICE (2007) ICE Specification for Piling and Embedded Retaining Walls, 2nd edn. Thomas Telford, London, UK.

ICE (2017) ICE Specification for Piling and Embedded Retaining Walls, 3rd edn. ICE Publishing, London, UK.

Jefferis SA (2014) Grouts and slurries. In The Construction Materials Reference Book, 2nd edn (Doran DK and Cather R (eds)). Routledge, Abingdon, UK, pp. 165-194. 
Geotechnical Engineering

Volume 171 Issue GE6
Treatment of bentonite fluid for

excavation into Chalk

Lam, Jefferis and Suckling
Jefferis SA and Lam C (2017) Using density to determine the solids content of construction slurries. Proceedings of the 19th International Conference on Soil Mechanics and Geotechnical Engineering, Seoul, Korea (Lee W, Lee J-S, Kim H-K and Kim D-S (eds)). Korean Geotechnical Society, Seoul, Korea, pp. $1695-1698$.

Lam C (2016) Evaluation of density-measurement methods for construction slurries. Geotechnical Testing Journal 39(3): 507-514.

Lam C and Jefferis SA (2014) Interpretation of viscometer test results for polymer support fluids. Proceedings of Sessions of the GeoShanghai 2014 International Conference, Shanghai, China (Ding W and Li X (eds)). American Society of Civil Engineers, Reston, VA, USA, Geotechnical Special Publication No. 242, pp. 439-449.

Lam C and Jefferis SA (2015) Physical properties of polymer support fluids in use and their measurement techniques. Geotechnical Testing Journal 38(4): 490-500.

Lam C, Jefferis SA and Martin CM (2014) Effects of polymer and bentonite support fluids on concrete-sand interface shear strength. Géotechnique 64(1): 28-39, https://doi.org/10.1680/geot.13.P.012.

Lam C, Jefferis SA, Suckling TP and Troughton VM (2015) Effects of polymer and bentonite support fluids on the performance of bored piles. Soils and Foundations 55(6): 1487-1500.

Liu SY (2010) Slurry Dewatering in Pipe Jacking Industry. PhD thesis, University of Leeds, Leeds, UK.

Menkiti CO, Davis JA, Semertzidou K et al. (2015) The geology and geotechnical properties of the Thanet Sand formation - an update from the Crossrail project. Proceedings of the XVI European Conference on Soil Mechanics and Geotechnical Engineering, Edinburgh, UK (Winter MG, Smith DM, Eldred PJL and Toll DG (eds)). ICE Publishing, London, UK, vol. 2, pp. 855-860.

Pennington M (2015) Diaphragm wall construction at Woolwich Arsenal Station box. Proceedings of Crossrail: A Specialist Foundation Construction Lessons Learnt Conference, London, UK. Federation of Piling Specialists, Bromley, UK, pp. 17-24.

Phillips NS (2016) Disaggregation of Soil during Slurry Pipe Jacking. $\mathrm{PhD}$ thesis, City University London, London, UK.

Schlosser F, Simon B and Morey J (1989) High capacity barrettes in a region of old underground quarries. Piling and Deep Foundations: Proceedings of the 3rd International Conference on Piling and Deep Foundations, London, UK (Burland JB and Mitchell JM (eds)). Balkema, Rotterdam, the Netherlands, pp. 119-130.

Suckling TP, Lam C, Jefferis SA and Pantling CJ (2011) Evaluation of causes of bleeding of free water from a bentonite slurry. Proceedings of the 36th Annual Conference on Deep Foundations, Boston, MA, USA. Deep Foundations Institute, Hawthorne, NJ, USA, pp. 401-407.

Symes C (2012) Engineered for value. Ground Engineering 45(7): $12-13$.

Verfel J (1989) Rock Grouting and Diaphragm Wall Construction. Elsevier, Amsterdam, the Netherlands.

Xanthakos PP (1994) Slurry Walls and Structural Systems, 2nd edn. McGraw-Hill, New York, NY, USA. 